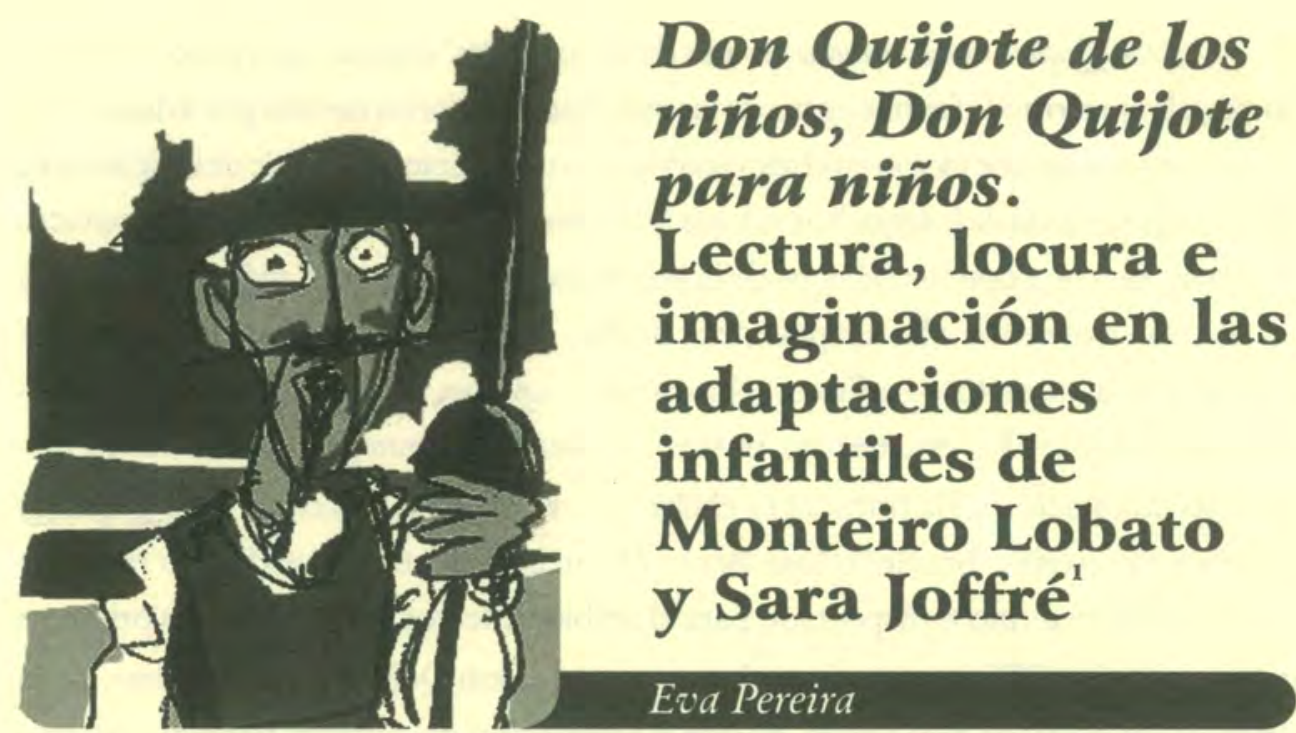

i observamos los trabajos pioneros de Charles Perrault y de los hermanos Jacobo y Guillermo Grimm, percibimos que las adaptaciones literarias se confunden con la historia misma de la literatura infantil-juvenil, llegando igualmente a configurarse como un subgénero de esta. Sin embargo, si estos primeros autores de fines del siglo XVII y comienzos del siglo XIX adaptaban las historias oriundas de la tradición oral de sus respectivos países, condensando y transformando los cuentos populares originales en historias destinadas a un público infantil y juvenil con su lenguaje e imágenes propias - y sirviendo después de modelos para las adaptaciones de los mitos y fábulas nacionales por escritores que pasarán a recogerlos y registrarlos, llevándolos a las escuelas a través de los libros de lecturas_- las adaptaciones literarias del siglo XX utilizaron los llamados clásicos literarios como su objeto privilegiado. En consecuencia, los niños y jóvenes de hoy tienen acceso fácil a las adaptaciones de la Odisea y de la Iliada, de Homero, de piezas de William Shakespeare, de las historias de la Bíblia y de los cuentos de las Mily una noches, entre muchos otros.

\footnotetext{
' Versión actualizada de la conferencia «Don Quijote para niños: Monteiro Lobato y Sarah Joffré. Cuestiones sobre literatura infantib), presentada en las Segundas Jornadas de la Asociación Peruana de Literatura Comparada (ASPLIC), «Quijotes. Discursos, relecturas, tradicionesn, 11 y 12 de octubre de 2005.
} 
Don Quijote de la Mancha es una de estas obras clásicas que pasó a formar parte del repertorio infantil a partir de las varias adaptaciones hechas por educadores y escritores artistas que vieron en el texto cervantino una fuente inagotable de imaginación, humor y enseñanza de los muchos valores humanos, lo que comprueba que el contacto con la literatura, y con los clásicos de la literatura, empiezan en la niñez, cuando los niños están expuestos a las adaptaciones hechas en libros, fragmentos reproducidos en libros de lectura, fotografías e ilustraciones, juguetes, series televisivas, películas y piezas infantiles. En este trabajo, buscaré analizar las estrategias discursivas de dos de estas adaptaciones: la primera es el libro Dom Quixote das crianças ${ }^{2}$ (Don Quijote de los niños), del escritor brasileño José Bento Monteiro Lobato, un verdadero resumen del clásico cervantino transportado para el ambiente lector del Brasil de las primeras décadas del siglo XX; la segunda es el texto teatral «Don Quijote de la Mancha», ${ }^{3}$ de la dramaturga peruana Sara Joffré, donde la adaptación del famoso texto al universo infantil es hecha a partir del recorte de tres aventuras del héroe manchego y de su fiel escudero y llevadas a la escena a través de las técnicas y métodos del teatro épico y didáctico de Bertolt Brecht.

\section{DON QUIJOTE DE LOS NIÑOS}

C onsiderado el fundador de la literatura infantil en Brasil, Monteiro Lobato (1882-1948) hace parte del grupo de escritores brasileños que, después de conocidos como autores de textos para adultos, pasarán a escribir también para niños, como es el caso de Graciliano Ramos, Vinícius de Moraes, Clarice Lispector, Mário Quintana, Érico Veríssimo, Cecília Meireles. Pero, a diferencia de ellos, el autor de Reinações de Narizinbo $0^{4}$ (Naricita) es hoy más conocido por sus textos destinados a los

\footnotetext{
${ }^{2}$ Para este trabajo se ha utilizado la siguiente edición: Monteıro Lobato, José Bento. Dom Quixote das criangas. 27. a ed. São Paulo: Brasiliense, 1994. El libro fue publicado por primera vez por la editora que pertenecía al mismo Monteiro Lobato. Véase Dom Quixote das crianças. São Paulo: Companhia Editora Nacional, 1936. El texto fue traducido al español dos años después y publicado en Argentina bajo el título Don Qujjote de los niños. Trad. de Benjamin de Garay. Buenos Aires: Editorial Claridad, 1938.

'Jorfré, Sara, «Don Quijote de la Mancha». En Cuentos de teatro para niños. Lima: Fondo Editorial del Banco Central de Reserva del Perú, 1998. El libro es el resultado de la compilación de las piezas escenificadas por el grupo Homero Teatro de Grillos, creado en 1963 por Sara Joffré y que se presentó en diversos espacios culturales y escuelas del Perú, preocupado en formar el público teatral entre niños y jóvenes.

${ }^{4}$ Una explicación del término reinapoôes se encuentra en el artículo «Descubriendo el Sitio do Picapau Amarelo. La literatura infantil de Monteiro Lobato y su universo mágicon de Alessandra de Souza Gibello, en este mismo número; véase nota 5. (Nota del editor).
} 
niños que por su producción, también de muy buena calidad literaria, para adultos. Inventor de un mundo de fantasía, un verdadero país de las maravillas, que es el Sitio do Picapau Amarelo (La quinta del benteveo, o pájaro carpintero amarillo), Lobato es también el creador de personajes inolvidables para los niños que entran en contacto con su obra: Emília, la muñeca de trapo, habladora e irreverente; el Vizconde de Sabugosa, un muñeco hecho de maíz, científico y adicto a la lectura; Lúcia o Narizinho, la niña de la nariz respingada; Pedrinho, el cazador valiente; Dona Benta, la buena e inteligente abuela de los dos niños traviesos y preguntadores, siempre con un libro en las manos; Tia Nastácia, la cocinera hábil y miedosa que cuenta a los niños las historias orales tradicionales de Brasil, las fábulas, los cuentos de terror.

En este mundo mágico, de características marcadamente rurales, donde Narizinho y Pedrinho se encuentran en las vacaciones de verano, ocurren los más sorprendentes hechos, siempre mediados por un libro, por una narrativa oral o por un comentario hecho a partir de una película, una música, una ilustración o cuadro, es decir, siempre a partir del diálogo con otros textos literarios y/o manifestación de la cultura erudita, masiva o popular, lo que hace que una de las características fundamentales de la obra de Lobato sea la intertextualidad. Es así que los niños pueden viajar al cielo o a los palacios de los cuentos de hadas, salir de una aventura con los dioses de la mitología griega e involucrarse en otra con los seres fantásticos de la selva brasileña o conversar con artistas del cine, conviviendo tranquilamente con seres y objetos de la realidad y de la fantasía, en un ambiente muy parecido al del realismo mágico de la literatura latinoamericana. ${ }^{5}$ Es justamente en este ambiente que un día se lee el libro de Miguel de Cervantes.

Personaje constante en la obra de Lobato, ${ }^{6}$ Don Quijote es el representante máximo y un verdadero modelo de la ficción y de la fantasía en la obra del autor de Reinações de Nariz̧inho. En sus libros, Monteiro Lobato aprovecha al famoso caballero como antecedente ilustre de la convivencia entre lo real y lo imaginario, posible a partir del ejercicio de la lectura, y lo invita a tomar un café en la sala del Sítio o a

\footnotetext{
${ }^{5}$ La aproximación entre la literatura infantil brasileña y el realismo mágico fue asumida por Machado a partir de una sugerencia del crítico literario cubano Joel Franz Rosell, quien identifica dos elementos fundamentales en la obra para niños de la escritora brasileña: la fantasía crítica y el realismo mágico. Véase MACHADo, Ana Maria. «Panorama de la literatura infantil brasileña». En МАснидо, Ana Maria y Graciela Montes. Literatura infantil: creación, censuray resistencia. Buenos Aires: Sudamericana, 2003, p. 77.

"Don Quijote forma parte del libro Memórias de Emilia (Sitio do Picapan Amarelo).
} 
emitir sus opiniones sobre otros famosos personajes de la literatura. Sin embargo, esa apropiación solamente es posible porque sigue la coherencia de Lobato en relación a la misma obra cervantina, donde el caballero, personaje inventado, ya hacía tales intervenciones y donde sus viajes extraordinarios también posibilitaban la mezcla entre realidad y ficción, verdad y mentira.

Como señala Marisa Lajolo, la adaptación de Monteiro Lobato es creativa y paródica desde el título, donde es construido un paralelo sonoro entre el título original, Don Quijote de la Mancha, y el título recreado, Dom Quixote das criangas, además de evidenciar la apropiación de la historia por sus lectores: el personaje no es más el representante de un lugar (La Mancha), sino el objeto de juego de los niños (as crianças). El libro es también la historia de una más de las aventuras de los nietos de Doña Benta y de sus muñecos maravillosos, la aventura de la lectura del libro de Cervantes: la obra Don Quijote de los niños es, entonces, la historia de una lectura exitosa. Y esta lectura empieza por un accidente producido por la curiosidad de Emília: interesada en las ilustraciones de Gustave Doré, la muñeca derrumba los dos pesados tomos de la obra del estante. El accidente sugiere a Dona Benta la idea de leerlo para los niños, pero luego percibirá que, por cuenta de la dificultad del lenguaje anticuado de la traducción portuguesa y también debido al tamaño de la historia, tendrá que buscar una forma alternativa de lectura, lo que va posibilitar al autor hacer la adaptación del clásico español al público infantil brasileño. La lectura da lugar entonces al relato, a la selección de los hechos más interesantes de la historia, al comentario sobre algunos de los pasajes claves del libro y a la sugerencia de continuación del debate acerca del Quijote a partir de la lectura de otros textos relacionados a los asuntos explorados en la obra. Y la lectora se transforma en mediadora entre los oyentes y la historia. El relato es, de este modo, una forma de aproximar a los niños del texto original de Cervantes y una forma eficiente de propaganda de ello, que deberá ser leído íntegramente cuando los oyentes estén crecidos.

A través de Dona Benta, Lobato cuenta a sus nietos y a nosotros sus lectores la historia del Quijote, pero siempre alertando que esta es una solución provisional hasta que los niños puedan leer el texto completo. Desde el comienzo, la buena

\footnotetext{
Véase LajoLo, Marisa. «Monteiro Lobato e Dom Quixote: viajantes nos caminhos da leitura». El pexto, un ensayo que estudia en detalle el libro de Monteiro Lobato, está disponible en la siguiente dirección electrónica < www.unicamp.br/iel/ site/graduacao/Quixote.rtf>. Consulta hecha el 6 de junio de 2006.
} 
señora, además de seguir de cerca el libro, siempre con este en las manos, confiesa la inferioridad de la adaptación frente al original. Algunos momentos son especialmente aclaradores de esa valorización de la lectura. Así sucede al inicio del relato:

-Hijos míos — dijo D. Benita, —esta obra está escrita en alto estilo, rico de todas las perfecciones y sutilezas de la forma, razón por la cual se tornó clásica. Pero, como ustedes todavía no tienen la necesaria cultura para comprender las bellezas de la forma literaria, no voy a leerles el libro sino contarles la historia con mis palabras. ${ }^{8}$

En otro momento, la abuela aprovecha comentarios de los niños para hacer alguna interpretación de la narrativa y para relacionarla a hechos próximos a la realidad de los niños:

-De hecho. Cuando ustedes crezcan y lean este capítulo de Cervantes, habrán de ver lo gracioso que es - y al mismo tiempo triste. La locura es la cosa más triste que existe..."

El autor aprovecha también la situación del relato para presentar lo que entiende como necesario en una buena adaptación infantil, lo que demuestra la conciencia de Lobato de su papel como formador de un público lector infantil presente y, por tanto, para la lectura de sus obras, y de la continuación de la formación de este mismo lector para la lectura de textos de la llamada literatura de los adultos:

Dona Benta interrumpió la narrativa para contestar una pregunta de Pedrinho. El niño quería saber si ella estaba contando la historia entera o solamente pedazos. -Estoy contando solamente algunas de las principales aventuras de D. Quijote, y resumidamente. Ah, jsi yo fuese a contar el D. Quijote entero la cosa iba lejos! Esa obra de Cervantes es bien larga... Solamente los adultos, gente de cerebro bien maduro, pueden leer la obra íntegra y alcanzarles todas sus bellezas. Para ustedes, pequeñitos, tengo que resumir, contando solamente lo que divierte la imaginación infantil. ${ }^{10}$

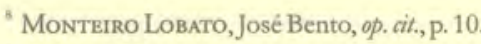

'Ibidem, p. 52.

${ }^{10}$ Ibidem, p. 70.
} 
$\mathrm{Y}$ así sigue hasta el final, siempre resaltando las cualidades del texto de Cervantes y la necesidad de que los niños se vayan preparando progresivamente para la lectura futura de los clásicos de la literatura universal. Dona Benta asume entonces el papel de una verdadera educadora, una lectora profesional y una competente animadora de la lectura: así como en el Quijote, lo que es homenajeado en Don Quijote de los niños es la lectura, presentada en toda su magia y riesgo.

Apropiación paródica de la obra de Cervantes, Don Quijote de los niños repite situaciones en que los oyentes, durante el relato, se transforman en el mismo Quijote; ya sea por el coraje y el deseo de pelear, como está en las pequeñas aventuras de Pedrinho; por el deseo de justicia, como ocurre con Narizinho; por la locura provisional por mucho imaginar, como pasa con la muñeca Emília, que imita al lector modelo que es el caballero andante.

\section{DON QUIJOTE PARA NIÑOS}

L

a otra posibilidad de adaptación literaria estudiada en este trabajo, aquella en que se recorta pocos episodios de una historia, es la que hace la dramaturga Sara Joffré en su «Don Quijote de la Mancha». En el cuento adaptado para la puesta en escena, la autora elige solamente tres de las aventuras del Quijote, sin presentar, como hace Monteiro Lobato, el final de la vida del caballero. En su libro Cuentos de teatro para niños, además de textos originales suyos donde la realidad y la tradición oral peruanas son destacadas, Sara Joffré presenta su adaptación del Quijote y de otros cuentos clásicos para niños, como El gato con botas, El flautista de Hamelin y Las ropas nuevas del rey, ${ }^{11}$ que sirven, según sustenta la autora, como un material de apoyo a profesores que deseen utilizar el teatro como estrategia de formación de lectores. Este objetivo pedagógico de los textos de Sara Joffré, inspirada en las propuestas de Bertolt Brecht, ${ }^{12}$ es evidente desde la primera página y se incluye en el objetivo general del teatro épico.

\footnotetext{
"Sara Joffré es una especialista en la adaptación infantil de los clásicos para el teatro. Su última publicación en esta área es Pinocbo (Lima: Bracamoros, 2005), una nueva edición de un texto publicado hace 40 años. Debe ser destacada también la labor de la autora en defensa de la utilización del teatro en la educación. Sobre ese último punto, véase sus traducciones de los libros Educación por el teatro, del brasileño Hilton Carlos de Araujo y de El niño y el teatro, de Roger Deldime.

${ }^{12}$ Es conocida el compromiso de Sara Joffré en favor del nombre de Bertolt Brecht en el Perú, no solamente en la práctica cotidiana de la puesta en escena de piezas traducidas, adaptadas e inspiradas en la obra del dramaturgo alemán, sino también en publicaciones de divulgación de las propuestas de él. Véase, por ejemplo, el libro Bertolt Brectsten el Perí-Teatro (Lima: Biblioteca Nacional, 2001).
} 
En su vertiente brechtiana, ese tipo de teatro es explícitamente didáctico y tiene como estrategias principales las preguntas constantes al público y una estructura abierta, donde la interpretación final debe ser dada por el espectador, acompañada por un juego dialéctico entre en el envolvimiento físico y emocional del público en la historia y la producción de un distanciamiento crítico frente a lo que es visto en la escena. Con el objetivo de mantener ese juego dialéctico, el teatro épico utiliza canciones infantiles y de origen popular, partes de textos canónicos de la literatura, números circenses, proverbios, adivinanzas, lo que hace de la función teatral una combinación de fiesta y reflexión sobre la historia social y política de los pueblos. Tal combinación solamente es posible, según Walter Benjamin, debido a la utilización premeditada de las interrupciones de la acción. Para eso, el teatro épico aprovecha al máximo el valor potencial de «los fenómenos dialécticos fundamentales del gesto», ya que mientras más se interrumpa al «que actúa, tanto mejor recibiremos su gesto»."3. De esa manera, aunque involucrado en el clima festivo del espectáculo, las interrupciones de la acción hacen que el espectador retenga la emoción y la diversión y hacen que se detenga un poco para reflexionar sobre el gesto del actor y sobre los contenidos de las frases.

Otra de las características esenciales del teatro épico es la presencia de un narrador, una especie de mediador entre el espectador y la historia presentada en la escena y también un organizador de la ficción frente a la realidad. De ahí que el narrador en el teatro de Bertolt Brecht es aquel que hace la apertura y el cierre de la pieza. De ahí también la caracterización de este teatro como épico, ya que, como se sabe, este adjetivo debería servir solamente para definir a los textos narrativos, cuentos y novelas, y pasa a participar de la definición de un teatro que rechaza la presentación objetiva y fría de los personajes y de la historia, prefiriendo la participación al mismo tiempo alegre y desconfiada del público y el comentario reflexivo sobre las acciones internas a la obra, en un ejercicio muchas veces metatextual.

Deseoso de enseñar al espectador adulto y contemporáneo de sus piezas el funcionamiento de la sociedad urbana e industrial del siglo XX, denunciar los males e intrigas de la economía capitalista y divulgar las intenciones revolucionarias del pensamiento marxista, Bertolt Brecht no tiene textos explícitamente escritos para

\footnotetext{
${ }^{13}$ Véase Walter Benjamin. Tentativas sobre Brecht. Prólogo y traducción de Jesús Aguirre. 2." ed. Madrid: Taurus, 1999, p. 44.
} 
el público infantil, porque este tipo de teatro, como ocurre en todos los productos culturales para los niños, tiene una historia más reciente. Pero, comprobado el valor artístico y el éxito del teatro épico, la metodología desarrollada por el dramaturgo alemán pasó a hacer parte del teatro y de la literatura destinada a los niños, aprovechando la costumbre de estos en interrumpir las narrativas para preguntar detalles sobre la historia y para comentar las acciones y el lenguaje de los personajes.

La adaptación hecha por Sara Joffré del texto de Miguel de Cervantes, «Don Quijote de la Mancha», sigue evidentemente la metodología ${ }^{14}$ del teatro brechtiano, empezando por la presencia de un narrador en el comienzo y en el fin de la pieza, un narrador que invita a los niños a acompañar la historia:

Yo quisiera contarles... pero no sé como empezar. ¿A ver que dicen Uds.? ¿Han oído hablar de Don Quijote? Un niño nos pidió que contáramos su historia. ¿Conocen Uds. la historia de Don Quijote? ¿Han oído hablar de él? Yo tampoco sé mucho. Pero aquí vienen los actores, preguntemos y podremos saber. ${ }^{15}$

El narrador se sitúa al comienzo como alguien que ignora lo que va pasar en la escena y afirma saber poco de la figura del Quijote, lo que le permite la identificación necesaria a la manutención de la atención de ellos en relación a las situaciones de las que participan los personajes. Pero, el diálogo siguiente, del mismo narrador, denuncia que él tiene ya una imagen formada del Caballero de la Triste Figura, imagen que es, además de un debate alrededor de la visión tradicional del Quijote, el tema mismo (casi como en una moraleja) de la pieza:

Podríamos decir que Don Quijote es la persona que teniendo muchos ideales, empezó muy tarde a luchar por verlos realizarse.

O que no supo distinguir entre luchar por el solo gusto de hacerlo, o luchar por algo que valiera la pena.

En fin, yo creo que es mejor que vean Uds. mismos, para que puedan opinar. ${ }^{16}$

\footnotetext{
"Uno de los textos citados por Sara Joffré en sus entrevistas más recientes es el estudio Brecht and Method, de Fredric Jameson, traducción hecha en Brasil por Maria Sílvia Betti y publicada bajo el título O método Brecbt (Petrópolis: Vozes, 1999).

15 JoFrré, Sara, op. cit., p. 89.

${ }^{16}$ Ibidem.
} 
Las dos explicaciones para la locura en las luchas del caballero son presentadas a los espectadores que, después de ver a los actores en la escena, podrán, según el mismo narrador, «opinan y construir ellos mismos su imagen del héroe. Pero, desde ahí, ya se presentan las posibilidades de interpretación y utilización didáctica del Quijote: el viejo loco porque, aunque cierto en sus intenciones, ya no tiene fuerzas para luchar; el viejo loco porque es incapaz de decidir entre la ficción y la realidad. Estas interpretaciones preliminares del Quijote, que podrían cerrar las posibilidades de lectura de los niños frente a la obra, son contrapuestas, en la despedida de la pieza, a través del diálogo final del narrador que, al repetir la información de que el Quijote no termina ahí, y que fueron presentadas solamente tres de sus aventuras, puede ser objeto de otras adaptaciones y lecturas por parte de los niños o mismo del teatro.

Luego de que la historia es abierta por los actores que interpretan la canción ritual de los comienzos de los cuentos orales ("La ronda de Felipito Felipón»), el mismo narrador presenta los episodios seleccionados en la adaptación del texto original, y lo hace de una manera asumidamente didáctica: «Don Quijote tuvo muchas aventuras, pero en una sola tarde todas no las podemos contans. ${ }^{17}$ Dicho esto, el narrador nombra las tres aventuras elegidas para la función: a) Aventura de la ayuda equivocada, b) Aventura con los Molinos de Viento, c) Aventura con los Odres de vino.

Marcadas las divisiones entre los tres actos centrales - donde los episodios son independientes entre sí- y la escena de apertura, el final repetirá el rito de las narrativas orales con la ronda, ahora resumida por los actores de «Felipito Felipón», y la despedida del narrador, que promete volver en otra oportunidad para contar otras aventuras del Quijote.

Caracterizado el texto como teatro épico, la otra cuestión que nos interesa de la adaptación infantil de Sara Joffré es su defensa de la lectura, hecha en el comienzo de la pieza, durante el diálogo entre la sobrina del caballero y la señora que cuida de ellos:

NIÑA:-¿Qué tiene el caballero señora que está tan transtornado?

SEÑORA:- Pues que se pasa el día entero leyendo libros que cuentan relatos de nobles paladines que luchan por causas perdidas y le ha dado a él por creerse uno de ellos.

\footnotetext{
${ }^{17}$ Ibidem, p. 90.
} 